\title{
Characteristics for the Identification of Children Who Commit Family Murder in South Africa
}

\author{
Melanie Carmen Moen ${ }^{1, *}$ \\ ${ }^{1}$ University of Pretoria, Gauteng, South Africa \\ *Corresponding Author: Melanie Carmen Moen, Early Childhood Education, University of Pretoria, \\ Groenkloof Campus, Pretoria, Gauteng 0002, South Africa. Email: melanie.moen@up.ac.za
}

\begin{abstract}
Children who commit family murder have been increasingly reported in the South African media. The implications of this type of violence have far reaching consequences for families and communities. Although family murder has been documented from the earliest of times, no research was conducted in this regard in South Africa, until now. In this qualitative study, nine documented cases of children who have committed family murder was analysed to gain an indepth understanding of the contributing factors of family murder by children. The individualand systemic reasons for these types of murders guided the research. The Interpersonal Parental Acceptance-Rejection Theory (IPARTheory) was used as theoretical framework. The researcher argues that the quality of the interaction between the parent and the child, as well as individual differences within a specific environment are central to committing murder. A summary of the general characteristics of children who commit family member murder was compiled. In this study the children were predominantly exposed to dysfunctional family environments that were characterised by problematic attachment to the caregiver/s, rejection, abuse and extreme parenting styles. The caregiver often expected the child to conform to their idea of the ideal child and non-conforming resulted in punishment and rejection. These children presented with interpersonal relationship problems, anxiety, aggression and fantasized about escaping their challenging home environments. In some of the cases the children abused
\end{abstract}


alcohol and drugs. In only a few of the cases signs of anti-social personality disorder were present. The family murders committed by children were predominantly committed by males. The weapons used in the murders were often everyday objects available in the environment. In this study, it was important to note that children who commit family murder have unique backgrounds and circumstances for committing these crimes. Therefore, the characteristics discussed in this article only serve as a guideline to understanding these children.

Key words: family murder, parricide, rejection, child murderer characteristics, dysfunctional families, IPART Theory

South African society is perceived as violent, and this violence is often attributed to a culture of violence (Leroux \& Mokhele, 2011). It is disturbing to note that $24.9 \%$ of all murders in South Africa are committed by a relative or household member (Statistics South Africa, 2013). No specific statistics on children who commit murder or family murder exist in South Africa. Academic knowledge of family murder is relatively scarce throughout the world (Walsh, Krienert, \& Crowder, 2008). International research revealed that $2 \%$ of murders in the United States are family murders committed by children (Heide, 2013). In South Korea, 1,100 murders were committed from 2006 to 2013, of which 381 were family murders by adults and children (Shon \& Lee, 2016).

Murder is seen by many as the most serious of all crimes, but when murder is committed by a young person, it is often even harder to comprehend. Family murder is the intentional and unlawful act of murdering a mother, father, or close family member (Fegadel \& Heide, 2015; Shon \& Lee, 2016). In this study, family murder referred to the murder of a close family member such as a father, mother, or sibling, as well as adoptive parents and extended family members. Therefore, the concept family murder refers to the murder of biological and extended family, caregivers, and adopted or foster families (Pillay, 2009). 
Although family murder represents a small percentage of all murders worldwide, it has far-reaching consequences for society and the family. While television and the Internet have brought us closer to violence within society, it is still disturbing when a young person is involved in murder. In an increasingly violent society such as South Africa where the murder rate has increased with 4.9\% from 2015 to 2016 (Evans \& Verster, 2016), it becomes imperative to understand violent crimes and the causes. While interest in crime has always been high, understanding why it occurs and what to do about it has remained a challenge. "Our inability to prevent crime is partly due to our challenges in understanding criminal behaviour, which is a complex phenomenon" (Bartol \& Bartol, 2014, p. 2). Lancaster (2013) is of the opinion that murder should be seen as a social problem that cannot be solved by policing alone. Far too little attention has been paid to violence-related crimes in South Africa, in particular relating to children, families, and young people.

Murder is often seen as a serious mental health and criminal justice problem that imposes an extraordinary human and social burden on society. The epidemiological criminological perspective embraces the importance of gaining new insights into issues from various perspectives by adapting to the ever-changing scientific theoretical and conceptual landscapes of different disciplines (Akers, Potter, \& Hill, 2012). This perspective also recognizes that individuals who engage in illegal behavior have a direct impact on various public health systems (Waltermauer \& Akers, 2013)).

In this article, the researcher argues that family murder committed by children is a societal problem that is broader than what the criminal justice system can cope with. Knowledge that can assist in identifying the risk factors associated with family murder is imperative. Early detection of risk factors by psychologists, communities, and schools can help prevent family murder committed by children. Awareness of early signs and identification of risk factors can make it possible to plan intervention strategies. 
This article describes the characteristics of family murders committed by children as presented in an in-depth qualitative study of nine cases of children who committed these crimes. The article will describe the research methodology that was used to determine the characteristics. The reasons for the selection of the IPARTheory as a theoretical framework will also be discussed. The general character traits of children who commit family member murder will be described and set out in this article.

\section{Children who commit family murder}

Family murder has persisted for centuries and is documented in various cultures throughout the world (Heide, 2013). It is often attributed to dysfunctional family dynamics, personal psychological challenges, and the availability of weapons (Flowers, 2013). Meyers and Vo (2012) stated that the number of accumulated systemic factors contribute to family murder by children. Therefore, one must be careful not to focus on single-factor models to understand this complex phenomenon.

Previous studies indicated that children who commit family murder often come from homes where accumulated neglect, physical punishment, and abuse existed. The absent father figure was also apparent in several studies. According to Flowers (2013), youths who commit family murder often have a history of psychological difficulties, were abused, or show signs of antisocial personality disorder. Psychological problems that these children presented with included depression, paranoid schizophrenia, and low self-esteem. Various family-related reasons are also given for these murders. Meyers and Vo (2012) stated that the accumulated factors associated with child neglect are often present when family murders are committed. These children are often exposed to violence (Flowers, 2013). DiCataldo and Everette (2008) stated that the ease with which youths can access weapons is also the cause for concern.

Family murders are predominantly committed by single perpetrators with a single victim (Fegadel \& Heide, 2015). When women commit these crimes, they often have an 
accomplice (Heide, 1993). Diem and Pizarro (2010) stated that fathers are often killed for physical abuse and mothers because of psychological and sexual abuse of their children (Flowers, 2013). When siblings are murdered, it is often due to stress, competition, unresolved conflict, psychological problems, or alcohol and drug abuse (Diem \& Pizarro, 2010). Children who commit family murder often do not have previous criminal histories and seldom get involved in criminal activities after the murders, possibly because the motivation for murder falls away after the murders have been committed (Dantas, Santos, Dias, Dinis-Oliveira, \& Magalhães, 2014). Meyers and Vo’s (2012) research indicated that adolescents who are not diagnosed with antisocial personality disorder have a good prognosis for rehabilitation.

Differences between children and adults who commit family murder are also apparent. Adult family murderers are often diagnosed with antisocial personality disorder or other psychiatric disorders. Young family murderers were often physically abused, have a history of psychological difficulties, or were diagnosed with antisocial personality disorder (Diem \& Pizarro, 2010; Flowers, 2013).

Heide suggested a typology for young family murderers. Her research revealed that family murder offenders are either dangerously antisocial, severely abused, or severely mentally ill (Heide, 2013). An analysis of media reports of various countries over the world suggested that family murderers often have the following characteristics:

- They act alone (sons only);

- $\quad$ Sons were the primary offenders;

- Use knives, blunt objects, personal weapons;

- Have been in a fight with the victim prior to the event;

- Were under the influence of alcohol and/or drugs and

- Were diagnosed with anti-social personality disorder (Boots \& Heide, 2006, p.431). 
As mentioned before, family murders committed by children constitute a small percentage of the overall murder rates in several countries. Nevertheless, these cases confront us with the need to identify the reasons and find possible solutions for family murders (Flowers, 2013). One way of identifying the risk factors relating to murders committed by children is by identifying the characteristics of these children.

\section{Theoretical Framework}

IPARTheory by Rohner was initially influenced by theories such as attachment theory, psychoanalysis, and Baumrind's theory. It was also known as PARTheory, but was later changed to IPARTheory to include intimate adult relationships throughout the life span. This theory states that parental acceptance or rejection by the attachment figure at any stage of a person's life is significant (Rohner, 2016). The current study used Interpersonal Parental Acceptance-Rejection Theory (IPARTheory). IPARTheory is an evidence-based theory of socialization of the life span development that aims to predict and explain major consequences and other correlates of interpersonal acceptance and rejection worldwide (Rohner, 2016). IPARTheory states that the perception of acceptance or rejection by the attachment figure has a significant influence on personality at any stage of a person's life. The theory is therefore focused on the quality of the relationship between caregiver and child. The child's perception of being accepted or rejected influences his or her future behavior (Rohner \& Khaleque, 2010). IPARTheory states that it is imperative that children experience acceptance by their attachment figures. If a child perceives himself or herself as being rejected, regardless of culture, age, or ethnicity, that child becomes more aggressive and emotionally unstable and has a negative worldview (Rohner, 2004). IPARTheory is embedded in the ecological perspective; therefore, the child must be understood within his or her specific context. The theory states the following: "We are what we are because of family (genetic and family influences) and because of where and when we grew up (sociocultural, cohort, and historical influences)" (Rohner, 2004, pp. 
$832,835)$. A central theme in this theory is that people over the world have a need for positive affirmation from significant others in their lives (Hughes, Blom, Rohner, \& Britner, 2005).

In the current study, the researcher attempted to understand the child who commits family murder from his or her unique context. The researcher argues that the quality of the interaction between the parent and the child, as well as personal stressors within a specific environment can lead to family murder by a child.

\section{Method}

This study elected a qualitative approach. Qualitative research is interested in describing behavior as it was documented and in understanding the meaning of the documented behavior (Joubert, Hartell, \& Lombard, 2016). This approach is often used to explore, interpret, and understand, which was the purpose of this study (Breakwell, Smith, \& Wright, 2012; Creswell, 2014; Rule \& John, 2011). In this study, nine cases of children under the age of 25 years were purposively selected for this study. One reason for selecting this age category was that children under the age of 25 are still physically developing into adults and often depend on family members for care in their early and middle 20s. Another reason for selecting this age group is the overwhelming research supporting the fact that brain development continues well into the third decade of life (Heide, 2013; Reyna, Chapman, Dougherty, \& Confrey, 2012; Steinberg, 2008). Professor Kathleen Heide, a leading expert in the field of parricide and family murder by children, states that extending the offender age to 24 makes sense as many individuals still live with their parents until their early 20s. Scientific findings also suggest that the brain is not fully mature before the age of 25 (Heide, 2013)

The researcher initially identified suitable South African cases of family murder committed by children for the period 1984 onward. Twenty-three cases were identified through the South African Law research database, law librarians, advocates, media articles, and referrals. The selected cases had to comply with specific criteria to be included in the study. 
Nine cases were selected for in-depth analysis and description after the availability and suitability of the documents had been determined. The specific criteria for the selection of cases were the following:

- $\quad$ The murder was committed by a child under the age of 25 years;

- The child has murdered or aided and abetted a murder of a family member(s).

- The child was found guilty by court of law of the murder(s) of a family member(s);

- Only South African cases from 1984 onward were considered;

- The child's background, description of crime, psychological and/or psycho-social report was available and

- A sentencing report was available.

The final selection was based on the above-mentioned selection criteria, the comprehensiveness of the case material, and the richness of the information available in the case documents. The cases were also a selection of diverse backgrounds, age, gender, and race. In six of the nine cases, the murders were committed on impulse, and in two of the cases, the murders were premediated. Mental disorders such as psychosis or schizophrenia were not present in any of the cases. In two of the cases in the study, the children presented with characteristics of antisocial personality disorder. These characteristics were only identified after the children committed the murders and did not meet all the necessary diagnostic criteria. The children in the two cases were also under the age of 18 at the time of the murders and could therefore not be diagnosed with antisocial personality disorder. The children also did not meet the necessary diagnostic criteria for conduct disorder.

Table 1 gives an outline of the selected cases from the youngest to the oldest child. Pseudonyms were used to protect the identities of the children in the study. The researcher 
obtained ethical clearance for this study from the ethical committee of the Faculty of Education, University of Pretoria.

Table 1. Selected cases from the youngest to the oldest participant

\begin{tabular}{|c|c|c|c|}
\hline Case & Race and ethnic group & $\begin{array}{l}\text { Age at time of the } \\
\text { offence }\end{array}$ & Offence \\
\hline Simone & $\begin{array}{l}\text { Indian } \\
\text { Female }\end{array}$ & 12 years & $\begin{array}{l}\text { She had her grandmother } \\
\text { murdered by two men. } \\
\text { She was present at the } \\
\text { murders. }\end{array}$ \\
\hline Selile & $\begin{array}{l}\text { African } \\
\text { Male }\end{array}$ & 14 years & $\begin{array}{l}\text { He murdered his } \\
\text { grandmother, mother, } \\
\text { brother and sister. }\end{array}$ \\
\hline Gideon & $\begin{array}{l}\text { White } \\
\text { Male }\end{array}$ & 15 years & $\begin{array}{l}\text { He raped his sister. He } \\
\text { murdered his mother, } \\
\text { father and sister. }\end{array}$ \\
\hline Mandla & $\begin{array}{l}\text { African } \\
\text { Male }\end{array}$ & 17 years & $\begin{array}{l}\text { He murdered his } \\
\text { stepfather. }\end{array}$ \\
\hline Neels & $\begin{array}{l}\text { White } \\
\text { Male }\end{array}$ & 17 years & $\begin{array}{l}\text { He murdered his mother } \\
\text { and father. }\end{array}$ \\
\hline Andre & $\begin{array}{l}\text { White } \\
\text { Male }\end{array}$ & 19 years & $\begin{array}{l}\text { He murdered his mother, } \\
\text { father and brother. }\end{array}$ \\
\hline Nico & $\begin{array}{l}\text { Indian } \\
\text { Male }\end{array}$ & 19 years & $\begin{array}{l}\text { He murdered his mother, } \\
\text { grandmother and } \\
\text { grandfather. }\end{array}$ \\
\hline Karel & $\begin{array}{l}\text { White } \\
\text { Male }\end{array}$ & 20 years & $\begin{array}{l}\text { He murdered his parents } \\
\text { with the help of his sister } \\
\text { and her boyfriend. }\end{array}$ \\
\hline Belinda & $\begin{array}{l}\text { White } \\
\text { Female }\end{array}$ & 22 years & $\begin{array}{l}\text { She had her mother } \\
\text { murdered while she } \\
\text { waited in the next room. }\end{array}$ \\
\hline
\end{tabular}

By applying a qualitative approach to inductive document analysis, a rich and in-depth understanding of the phenomenon could be developed. The main advantage of using documents as data sources is that the researcher can access a diverse sample of documents and check broad ideas. Documents also lend themselves to the possibility of rich descriptions of content. The 
researcher is able to verify themes through various data sources. According to McLeod (2011), another advantage of sources such as documents is the fact that they were not created for research purposes and have therefore not been influenced by the researcher. One of the disadvantages of using document analysis is that the documents were written in a specific language for a specific audience and context and not necessarily for research purposes (Altheide, Coyle, DeVriese, \& Schneider, 2008). A case study design was followed to get an in-depth understanding of children who commit family member murder.

Qualitative content analysis was used for the data analysis process. By using qualitative content analysis as data analysis technique in this study, the researcher wanted to reduce the complexity of a collection of texts (Bauer \& Gaskell, 2000). To put each case in its context, the individual history was evaluated and briefly discussed in the research to establish similarities in the backgrounds. An eight-stage process (see Table 2) was followed to analyze and interpret the qualitative data.

Table 2. Qualitative content analysis

\begin{tabular}{|c|c|}
\hline Stage & Description \\
\hline Stage 1: Overview & $\begin{array}{l}\text { - The researcher developed a broad overview } \\
\text { of the raw materials. } \\
\text { - } 9 \text { suitable cases meeting the criteria were } \\
\text { selected. } \\
\text { - } \quad \text { The selected cases were read a second time. } \\
\text { - } \quad \text { General themes were identified. } \\
\text { - A coding system was developed. }\end{array}$ \\
\hline Stage 2: Open and axial coding & $\begin{array}{l}\text { - Open-coding: A smaller sample of the } \\
\text { documents were read. One randomly selected } \\
\text { case (following the selection criteria) was } \\
\text { analysed. Noticeable patterns were recorded, } \\
\text { if noted. Emerging and predetermined codes } \\
\text { were used during analysis. Axial coding: } \\
\text { Entire sample of documents were reviewed. } \\
\text { Specific passages belonging under theme } \\
\text { categories identified in initial open-coding } \\
\text { phase were tagged. }\end{array}$ \\
\hline Stage 3: Selective-coding & $\begin{array}{l}\text { The researcher combed through the } \\
\text { documents in search of miscoded passages } \\
\text { and discrepant evidence. }\end{array}$ \\
\hline Stage 4: Independent analysis & $\begin{array}{l}\text { - An independent researcher verified the } \\
\text { analysis. }\end{array}$ \\
\hline Stage 5: Description & $\begin{array}{l}\text { - Description of cases, as well as themes for } \\
\text { analysis were compiled. The coding system }\end{array}$ \\
\hline
\end{tabular}




\begin{tabular}{|l|c|}
\hline Stage & Description \\
\hline Stage 6: Discussion of themes & $\begin{array}{l}\text { was then used to generate themes for the } \\
\text { study. The themes were linked to the major } \\
\text { findings of the study. The findings were } \\
\text { linked to multiple perspectives and specific } \\
\text { evidence. }\end{array}$ \\
\hline Stage 7: Interpretation and verification & $\begin{array}{l}\text { A detailed discussion of interconnecting } \\
\text { themes were given. }\end{array}$ \\
\hline Stage 8: Comparison and theories & $\begin{array}{l}\text { Interpretation of meaning derived from the } \\
\text { study. Interviews with experts in the field } \\
\text { were conducted to verify themes. }\end{array}$ \\
\hline
\end{tabular}

Adapted from Wesley (2010) and Creswell (2014).

In this study, the data collection and data analysis were not simultaneous processes, as is often the case in qualitative studies (Creswell, 2014). The researcher only analyzed the data when all the relevant documents had been collected and linked to the specific cases. To protect the study from possible subjectivity, the researcher only looked at prominent themes that emerged from the document analysis and related these themes back to relevant literature and theory.

The phenomenon as presented by each case as well as the interlinking themes of all the cases in the study was analyzed and interpreted. Therefore, this study was reflexive in nature and intent (Kruger, 1988). The research attempted to highlight, through the analysis of documents, how these children made sense of the world they live in as well as their perceptions of the influences of the various systems on their meaning-making. Within the phenomenological perspective, the art of interpreting is within context, because people relate experience to a relevant context. Therefore, the researcher was always aware of the context of experience in the cases under study. Five experts who had experience and knowledge of children who had committed family murder were interviewed for the study. They were from law, law enforcement, journalism, and social work, respectively. The experts provided their specific case knowledge and experiences of family murder. 


\section{Findings and Discussion}

The results in this study related to problematic attachment, family dysfunction and individual psychological problems. In several of the cases the attachment with the primary caregiver was problematic. Attachment relates to the dependence of the child on the primary caregiver. When secure attachment takes place, the primary caregiver is attentive to the child's needs (Barnes \& Schakelford, 2016). In a secure relationship between caregiver and child, the child will feel safe and will have energy to explore their environment (Beeney et al., 2015). Moral development is also associated with attachment and relates to adhering to society standards and rules, as well as with emotional regulation (Termini, Golden, Lyndon \& Scheaffer, 2009). When the bond between caregiver and child is not secure it can result in anxious-, avoidant- or disorganised attachment (Russell \& King, 2016). Disorganised attachment relates to the inconsistent behaviour of a parent. A link between disorganised attachment and aggression in children was established in this study. Anxious attachment relates to feelings of insecurity as well as aggression against the caregiver. Avoidant attachment is also linked with aggression and passive isolation, mostly by boys. Children who show signs of avoidant attachment do not react when the care giver leaves the room or is not available (Lyons-Ruth, 1996).

In all the cases in this study, attachment was identified as problematic. Disorganised- and anxious attachment were identified in several of the case studies. The children in this study were often exposed to inconsistent and/or aggressive behaviour from the parent or caregiver. For example in Nico's case he had limited contact with his father and his relationship with his mother was characterised by aggression, physical-, sexual- and verbal abuse. Nico's mother often changed her mind after she promised something. The unpredictable behaviour of a parent is often associated with disorganised attachment (Lyons-Ruth, 1996). Children who present with anxious attachment feel unsafe and can develop feelings of aggression towards the parent. These children are often scared to show their true emotions, as this might result in 
further rejection from the parent. They generally feel unsafe and present with low-selfesteem (Holmes, 1993, p. 84). In Simone's case her parents never intevened when her grandmother insisted Simone move in with her. She was moved on several occassions between her parents home and her grandmother's residence. Simone witnessed her father being abused by his own mother, and Simone in turn was also physically abused by her father.

A central theme in the IPARTheory is that people over the world have a need for positive affirmation from significant others in their lives, as well as a need for acceptance (Hughes et al., 2005). However, rejection was another major finding of the study. In all cases, signs of rejection were identified. Bondü and Richter (2016) identified a link between sensitivity to rejection and aggression. Downey and Feldman (1996) determined that rejection was associated with feelings of jealousy, depression, and aggression. According to the IPARTheory (Rohner \& Khaleque, 2010), a person who feels rejected often display feelings of hostility, aggression, and emotional instability regardless of culture, gender, or age. In all the cases in this study, the participants presented with aggression. In cases such as Nico, Neels, Andre, and Simone, depression was also noted. Acceptance is associated with feelings of worthiness and positive interaction with others (Crockenberg \& Leerkes, 2003).

The role of the mother was also significant in the study, but limited literature exists that specifically focus on the role of the mother and family murder. In the two cases in this study of family murder involving young women, the mother figures were described as domineering. It was interesting to note that they were the family members who were murdered in the two case studies.

In several of the cases the children had no criminal histories before the murders. The literature indicates that persons who commit family murder, seldom get involved with criminal offences before or after the murders (Dantas et al., 2014; Marleau et al., 2006; Heide, 2003). In two of the cases in the study it was possible to track the progress of the participants several 
years after the murders. In both cases the participants adjusted well after the murders. They were married and had children of their own.

In this study, the murders were predominantly committed by male offenders, as was also found in the literature (Barnett, Miller-Perrin, \& Perrin, 2011; Fegadel \& Heide, 2015). The offenders in this study all lived with the murdered family member(s) at the time of the murders; this was often reported in the literature as well (Dantas et al., 2014). In this study, the father figures were either absent or a dysfunctional relationship with the child was reported. Marleau et al. (2006) identified in their study that family murderers regularly had an absent father in their lives. In this study, the dysfunctional relationships between fathers and children were significant. For instance, Gideon described his father as extremely strict and Selile had limited contact with his father. The paternal relationships often involved little support and guidance.

The children in this study did not present with behavior problems at school, but in some cases, the emotional and physical neglect of these children was reported. An important theme was that the majority of these children had difficulties with interpersonal relationships with their peers. In some of the cases, the children were isolated from friends, and in other cases, they had very few or no friends. No specific literature exists relating to interpersonal relationships of children who commit family murder, but this theme was important in the study.

In several of the cases the children experienced extreme conflict at home. In some of the cases the parents abused alcohol and in the majority of the cases the children were exposed to physical-, sexual and verbal abuse. The literature indicates that children who commit family murder are often exposed to abuse of various forms (Flowers, 2013; Heide, 2003; Fegadel \& Heide, 2015). Alcohol and drug abuse by the children in this study was present in four of the nine cases. The drug or alcohol abuse by the children were associated with an underlying desire to escape dysfunctional life experiences. Literature relate drug abuse with negative life experiences. Children who are abused are at risk to develop a drug dependency (Barnett et al., 
2011). Strict parenting styles are also associated with drug abuse (Hinnant, Erath \& El-Sheikh, 2015). The link between adolescent alcohol abuse and murder has also been established by DiCataldo and Everett (2008).

In all the cases in this study, the children presented with anxiety and aggression. Anxiety influences a person's general day-to-day functioning. People who are anxious find it difficult to adjust emotionally, show signs of low self-esteem, and tend to worry extensively (American Psychiatric Association, 2013). Environmental stressors and emotional maladjustment to daily circumstances are associated with anxiety (Ramsden, 2013). In several of the cases, the children were exposed to unstable and stressful home environments. In Neels's case, for instance, his father spoke to him about committing suicide. Simone's father committed suicide after discussing his suicide plans with her. Mandla and Selile were moved between homes and Mandla was often exposed to violence in his home. These environmental stressors contributed to extreme anxiety in these cases. Belinda's mother, for instance, often criticized her and threatened and physically abused her on a regular basis. These factors contributed to feelings of insecurity and aggression. Gideon struggled to live up to his father's idea of an ideal child, which could have resulted in feelings of aggression, and Andre wrote in his letters to his girlfriend that he could not live up to his father's expectations. The systemic factors, combined with the factors affecting the individuals in this study, contributed to feelings of insecurity, anxiety, and aggression. IPARTheory is embedded in the ecological perspective; therefore, the child must be understood within his or her specific context (Rohner, 2004). In this study, it was also imperative to understand the child within his or her specific and unique context.

The availability of weapons was also noted in the study. In all the cases the weapons were readily available to children. In Neel's case, he used a cricket bat and in Selile's case an axe that was used for chopping wood was used. Nico used the pistol that he had to secure for his mother every evening, to murder his mother, grandfather and grandmother. 


\section{The Character Traits of Children Who Commit Family Murder}

In this study, the researcher attempted to understand and describe the phenomenon of children who commit family murder as precisely and accurately as possible. To describe the child who commits family murder, a narrative of the characteristics of these children is presented below. The narrative was compiled by using the main themes as they presented through qualitative content analysis. As this study was a qualitative study, the characteristics are used as a guideline to understand the child who commits family murder. Future research is suggested to verify the characteristics identified.

\section{The child who commits family murder-The character traits}

The child who commits family murder is often part of a family where the attachment with the primary caregiver is problematic. These children rarely come from warm, supportive, and safe home environments. Very little emotional support and guidance is given to the child. Often, the parents do not understand the child's emotional needs. At times, the parents expect the child to deal with traumatic, life-changing events such as loss or the transition from one family home to another without parental guidance and support.

Various forms of abuse were identified in several of the homes of the children who committed family member murder. When these children are exposed to abuse (e.g., physical, sexual, and/or verbal) by one parent, the other parent or caregiver generally does not intervene or protect the child from the abuse. These children are often left to fend for themselves and to make sense of important life events they are not physically and psychologically equipped to handle. The accumulated negative events and experiences presented over several years leave these children with feelings of rejection and anxiety.

The home becomes a place where the child is not allowed to be himself or herself. The parent expects the child to conform to the parental perception of the "ideal" child, and to behave in a certain manner or face rejection from the parent. The father figure is generally absent or, in cases where the father is present, he is not supportive and encouraging. Extreme parenting styles are prominent in these homes and can present from permissive to extremely authoritarian styles. These children seldom present with behavior problems at school or at home before the murders, and the murder of (a) family member(s) is often their first serious offense. 
A significant theme in this study was the children's deep desire to escape from their dysfunctional life situations. In some of the cases, the children fantasized about a better life, and in others, they attempted suicide. Substance abuse was another way of escaping home circumstances, but this was also related to other environmental stressors in this study.

On an interpersonal level, these children have difficulty to establish acceptable relationships with their peers, and some of them are socially isolated. The inability to establish adequate relationships intensifies their feelings of rejection and worthlessness. In all the documented cases, the children who committed these crimes lived with the parent(s) they murdered.

The accumulation of personal and systemic stressors and events that presented over years contributed to the child ultimately acting on his or her suppressed feelings of anger and aggression at a seemingly insignificant moment by committing murder.

In this study, it was important to take into account the unique and individual differences of the different cases. The individual and systemic factors influenced each other and could not be seen in isolation. Therefore, the characteristics are offered only as a guideline for professionals and communities to identify risk factors and plan preventive measures.

\section{Conclusion}

Although family murder committed by children has been studied in other countries, this study was the first study of its kind in South Africa. Family violence affects people all over the world and South Africa is no exception. In this study, the nine cases were representative of the South African population. The cases represented population groups and genders.

In this study, the systemic factors related to family dysfunction, problematic attachment, rejection, and extreme parental styles were identified as significant, as were personal factors related to feelings of rejection, anxiety, depression, and aggression. Further research in this field is suggested. 


\section{Declaration of Conflicting Interests}

The author(s) declared no potential conflicts of interest with respect to the research, authorship, and/or publication of this article.

\section{Funding}

The author(s) disclosed receipt of the following financial support for the research, authorship, and/or publication of this article: The author received funding from the National Research Foundation of South Africa, as well as the Akademie vir Wetenskap en Kuns for the research of this article

\section{References}

Akers, T.A., Potter, R.H. \& Hill, C.V. (2012). Epidemiological Criminology: A Public Health Approach to Crime and Violence. Hoboken: Wiley Publisher.

Altheide, D., Coyle, M., DeVriese, K., \& Schneider, C. (2008). Emergent qualitative document analysis. Handbook of emergent methods, 127-151.

American Psychiatric Association (2013). Diagnostic and statistical manual of mental disorders (5th ed.). Washington, DC: Author.

Barnett, O.W., Miller-Perrin, C.L., Perrin, R.D. (2011). Family Violence across the lifespan: An introduction. California: Sage.

Bartol, C.R., \& Bartol, A.M. (2014). Criminal behaviour: A psychosocial approach. New Jersey: Prentice-Hall Inc.

Bauer, M.W. \& Gaskell, G. (2000). Qualitative researching with text, image and sound: A Practical handbook. London: Sage Publications.

Beeney, J.E.; Stepp, S.D.; Hallquist, M.N.; Scott, L.N.; Wright, A.G.C \& Ellison, W.D. (2015). Attachment and social cognition in Borderline Personality Disorder: Specificity in relation to Antisocial and Avoidant Personality Disorders. Personlaity Disorders: Theory, Research and Treatment, 6(3), 207-215.

Bondü, R. \& Richter, P. (2016). Linking forms and functions of aggression in adults to justice and rejection sensiticity. Psychology of Violence, 6(2), 292-302. 
Boots, D.P. \& Heide, K.M. (2006). A content analysis of available reports across cultures. International journal of offender therapy and comparative criminology, 50 (4), 418-445.

Breakwell, G.M.; Smith, J.A.; \& Wright, D.B. (2012). Research Methods in Psychology $4^{\text {th }}$ edition. London: Sage.

Creswell, J.W. (2014). Research design: qualitative, quantitative, and mixed methods approaches $\left(4^{\text {th }}\right.$ ed.). London: Sage Publications.

Crockenberg, S.C. \& Leerkes, E.M. (2003). Parental acceptance, postpartum depression and maternal sensitivity: Mediating and moderating processes. Journal of Family Psychology, 17(1), 80-93.

Dantas, S., Santos, A., Dias, I., Dinis-Oliveira, R. J., \& Magalhães, T. (2014). Parricide: a forensic approach. Journal of forensic and legal medicine, 22, 1-6.

DiCataldo, F. \& Everett, M. (2008). Distinguishing juvenile homicide from violent juvenile offending. International Journal of Offender Therapy and Comparative Criminology. 52(2), 158-174.

Diem,C. \& Pizarro, J.M. (2010). Social Structure and family homicides. Journal of Family Violence, 25, 521-532.

Downey, G. \& Feldman, S.I. (1996). Implications of rejection sensitivity for intimate relationships. Journal of Personality and Social Psychology, 70(6), 1327-1343.

Fegadel, A.R. \& Heide, K.M. (2015). Double parricide: An in-depth look at two victim homicides involving parents as victims. Behavioral Sciences and the Law, 33, 723-739.

Flowers, B.R. (2013). The dynamics of murder: Kill or be killed. Boca Raton: CRC Press.

Heide, K.M. (2013). Understanding parricide: When sons and daughters kill parents. New York: Oxford university Press.

Heide, K.M. (1993). Juvenile involvement in multiple offender and multiple victim parricied. Journal of Police and Criminal Psychology, 9 (2). 53-64.

Hinnant, J.B.; Erath, S.A. \& El-Sheikh, M. (2015). Harsh parenting, parasympathetic activity, and development of delinquency and substance abuse. Journal of Abnormal Psychology, 124(1), 137-151.

Holmes, J. (1993). John Bowlby \& Attachment Theory. London: Routledge.

Howe, D. (2005). Child Abuse and Neglect. New York: Palgrave Macmillan.

Hughes, M.M.; Blom, M.; Rohner, R. \& Britner, P.A. (2005). Bridging parental acceptancerejection theory and attachment theory in the pre-school strange situation. Ethos, 33(3), $378-401$. 
Joubert, I.; Hartell, C. \& Lombard, K. (2016). Navorsing: ' $n$ Gids vir die beginnernavorser. Pretoria: Van Schaik Publishers.

Kemp, C. (2012, August 22). Griekwastad deurbraak! Volksblad. Retrieved from http://0www.samedia.uovs.ac.za.innopac.up.ac.za/cgiin/getpdf? year $=2012 \&$ refno $=8857 \&$ topic $=15$

Kohlbacher, F. (2005). The use of qualitative content analysis in case study research. Forum: Qualitative Social Research, 7 (1), Art. 21, Retrieved from http://nbnresolving.de/urn:nbn:de:0114-fqs0601211

Kruger, D. (1988). An introduction to phenomenological psychology. Kenwyn: Juta.

Lancaster, L. (2013). Where do murders occur in South Africa. Retrieved from http://www.issafrica.org/iss-today/where-do-murders-occur-in-south-africa

Le Roux, C. S., \& Mokhele, P. R. (2011). The persistence of violence in South Africa's schools: In search of solutions. Africa Education Review, 8(2), 318-335. doi:10.1080/18146627.2011.602847.

Loebler, R. \& Farrington, D.P. (2000). Young children who commit crime: Epidemiology, development origins, risk factors, early intervention, and policy implications. Development and Psychopathology, 12, 737-762.

Lyons-Ruth, K. (1996). Attachment relationships among children with aggressive behavior problems: The role of disorganized early attachment. Journal of Consulting and Clinical Psychology. 64 (1), 64-73.

Marleau, J.D., Auclair, N., \& Millaud, F. (2006). Comparison of factors associated with parricide in adults and adolescents. Journal of Family Violence, 21, 321-325.

McLeod, J. (2011). Qualitative research in counselling and psychotherapy (2 ${ }^{\text {nd }}$ ed.). London: Sage Publications.

Meyers, W.C., \& Vo, E.J. Adolescent parricide and psychopathy. International Journal of Offender Therapy and Comparative Criminology, 56(5), 715-729.

Myburgh, M. (2014). Pupil, 16, murders grandmother with sword. Roodepoort Record.

Retrieved from http://roodepoortrecord.co.za/2014/12/17/pupil-16-murdersgrandmother-sword/

Newhill, C.E. (1991). Parricide. Journal of Family Violence. 6, 375-394.

Ramsden, P. (2013). Understanding abnormal psychology: Clinical and biological perspective. Londen: Sage.

Rohner, R.P. (2004). The parental “Acceptance-Rejection Syndrome”: Universal correlates of perceived rejection. Review of general Psychology, 5, 382-405. 
Rohner, R.P., \& Khaleque, A. (2010). Testing Central Postulates of parental acceptancerejection theory PARTheory: A Meta-Analysis of Cross-cultural studies. Journal of Family Theory \& Review, 2, 73-87.

Rohner, R.P. (2016). Introduction to Interpersonal Acceptance-Rejection Theory

(IPARTheory) and Evidence. Online Readings in Psychology and Culture, 6(1). Afgetrek van http://dx.doi.org/10.97072307-0919.1055

Rule, P. \& John, V. (2011). Your guide to case study research. Pretoria: Van Schaik Publishers.

Russell, D.R. \& King, A.R. (2016). Anxious, hostile, and sadistic: Maternal attachment and everyday sadism predict hostile masculine beliefs and male sexual violence. Personality and Individual Differences, 99, 340-345.

Shi, Z. (2011). Dilemmas in using phenomenology to investigate elementary school children learning English as a second language. In Education, 17(1), 3-13.

Shon, P.C. \& Lee, J. (2016). Evidence of Convergent Validity: A comparative analysis of sentencing verdicts and newspaper accounts of South Korean parricides. Asian Criminology, 11, 1-19.

Statistics South Africa. (2013). Victims of crime survey. Retrieved from http://beta2.statssa.gov.za/

Termini, K.; Golden, J.A.; Lyndon, A.E. \& Sheaffer, B.L. (2009). Reactive Attachment disorder and cognitive, affective and behavioral dimensions of moral development. Behavioral Development Bulletin. 15(1), 18-28.

Walsh, J.A., Krienert, J.L., \& Crowder, D. (2008). Innocence lost: A gender-based study of parricide offender, victim, and incident characteristics in a national sample, 1976-2003. Journal of Aggression, Maltreatment \& Trauma, 16 (2), 202-227.

Waltermauer, E., \& Akers, T.A. (2013). Epidemiological Criminology: Theory and Practice. Oxon: Routledge.

Wesley, J.J. (2010, April 9-10). Qualitative document analysis in political science. Amsterdam: T2PP Workshop Vrij Universiteit. Retrieved from https://www.poltext.org/sites/poltext.org/files/p2wesley._09102010_131253.pdf 